\title{
Modified organized ophthalmology pre-internship in China
}

\author{
Dongxuan Wu\#, Yifan Xiang", Xiaohang Wü, Jingjing Chen, Yuxian Zou, Zhenzhen Liu, Haotian Lin, \\ Yizhi Liu*
}

State Key Laboratory of Ophthalmology, Zhongshan Ophthalmic Center, Sun Yat-sen University, Guangzhou, China

Contributions: (I) Conception and design: Y Liu, H Lin, Z Liu; (II) Administrative support: H Lin; (III) Provision of study materials or patients: Z Liu, Y Xiang, Y Zou; (IV) Collection and assembly of data: D Wu, X Wu, J Chen; (V) Data analysis and interpretation: D Wu, Y Xiang; (VI) Manuscript writing: All authors; (VII) Final approval of manuscript: All authors.

\#These authors contributed equally to this work.

*The author is senior author.

Correspondence to: Haotian Lin; Zhenzhen Liu. Zhongshan Ophthalmic Center, Sun Yat-sen University, 7\# Jinsui Road, Guangzhou 510000, China. Email: gddlht@aliyun.com; liuzhenzhen@gzzoc.com.

Background: Medical pre-internship plays a crucial role in medical education promoting early involvement of students in clinical setting and helping them explore potential interest of specialty. However, there is currently no specifically designed pre-internship curriculum in China. Using ophthalmology as a pilot field, we have set up a modified organized pre-internship curriculum and evaluated its effectiveness and students' feedback in this study.

Methods: In this prospective noncomparative study, 42 junior undergraduate medical students were enrolled in the organized ophthalmology pre-internship. The effects of organized pre-internship on student performance were evaluated by difference of post- to pre-lecture scores by paired $t$-test. The effects of baseline knowledge level and gender on performance improvement were analyzed by independent $t$-test. Student satisfaction comparing organized pre-internship with traditional pre-internship was measured by questionnaire.

Results: The difference of post- to pre-lecture scores of all participants was $6.21 \pm 2.02(\mathrm{P}<0.0001)$. The improvement in post- to pre-lecture scores of students with low knowledge level $(7.08 \pm 1.85)$ was significantly higher than that of students with high knowledge level $(4.81 \pm 1.42)(\mathrm{P}<0.0001)$. Gender did not influence student performance. The responses to the questionnaire showed that most of students were more satisfied with the organized pre-internship than traditional pre-internship.

Conclusions: The organized pre-internship significantly improved student performance and satisfaction. Performance improvement in students with low knowledge level was more obvious. Compared to traditional pre-internship, the organized pre-internship showed advantages in improving student performance as well as promoting learning enthusiasm. Instructors played an essential role in the organized pre-internship teaching system.

Keywords: Organized pre-internship; medical education; ophthalmology pre-internship; early involvement in clinical practice

Submitted Feb 17, 2020. Accepted for publication Aug 21, 2020.

doi: 10.21037/atm-20-1651

View this article at: http://dx.doi.org/10.21037/atm-20-1651 


\section{Introduction}

Pre-internship or fore-observation, is also known as physician shadowing in some countries. Transition from a medical student to a physician is a challenging process and may bring great stress for trainees (1-3). Aim of preinternship in medical education is to help students to ease the transition. Aims of pre-internship are not only to teach medical knowledge but also to help medical students to learn soft skills in clinical practice, including how to communicate with patients $(4,5)$, and explore potential interest in medical specialty $(6,7)$. Previous study found that a supervised pre-internship before first job would be of great benefit (8). It is demonstrated that pre-internship can increase students' learning enthusiasm (9), provide greater insight into the clinical role $(10,11)$, and help students to make career choices earlier (12).

In China, many medical colleges encourage junior medical students to take part in medical pre-internship, and some medical colleges consider pre-internship as prerequisite to medical internship (13). However, junior medical students in pre-internship know little medical knowledge, and courses designed for senior medical students are not compatible with junior medical students' knowledge scope. Despite its importance, in China, purposes of medical preinternship have not been clearly defined. There is currently no specifically designed curriculum for medical preinternship and pre-internship does not play its due role in helping medical students to complete career transition (14). It is of great urgency to optimize the setting of medical preinternship in China to improve education quality (14).

Taking ophthalmology pre-internship as a pilot, we have set up an organized pre-internship curriculum based on rationale of "classroom, clinical practice, sharing and feedback". This study aimed to evaluate the effectiveness of the modified organized pre-internship and to assess student satisfaction to this curriculum. We present the following article in accordance with the STROBE reporting checklist (available at http://dx.doi.org/10.21037/atm-20-1651).

\section{Methods}

\section{Research process}

The study enrolled 42 Grade-two medical students who took part in the one-week modified organized preinternship in the Zhongshan Ophthalmic Center during their summer vacation. Only students who had participated in traditional pre-internship can evaluate and compare the modified organized pre-internship to traditional medical pre-internship, thus, inclusion criterion was previous participation in traditional pre-internship. All students had a pre-lecture test at baseline. They also had a postlecture test and filled in questionnaire after completion of pre-internship. The content of pre- and post-lecture tests were exactly the same. The participants did not know in advance that they would do the same test. Therefore, the post-lecture scores could reflect the improvement in student performance after completion of organized preinternship. The study was conducted in accordance with the Declaration of Helsinki (as revised in 2013). All the procedures in this study were arranged strictly with the approval of the institutional review board of Zhongshan Ophthalmic Centre of Sun Yat-sen University (IRB-ZOCSYSU). Written informed consents have been obtained from all participants.

\section{Modified organized pre-internship for ophthalmology}

\section{Rationale of course design}

The schedule of the one-week organized pre-internship is presented in Figure 1. The curriculum was based on rationale of "classroom, clinical practice, sharing and feedback". Students learned some basic concepts of ophthalmology and clinical research. Ophthalmic examinations and other soft skills were introduced during clinic observations and practicing. In addition, teachers organized students in the same group to discuss and summarize everyday key points. A debate on pros and cons of excimer laser corneal surgery was conducted to encourage students to initiatively learn about this common ophthalmic practice. Specific questionnaire was given to evaluate student satisfaction of the pre-internship from various aspects.

\section{Course components}

(I) Basic theory: Ocular anatomy, diagnosis and treatment of cataract (a common eye disease), clinical data collection and organization, reference search.

(II) Soft skills and clinical practice: Common ophthalmic examinations, doctor-patient communication, humanistic care, and routines of inpatient department.

(III) Bonus case discussion: Three cases were given from which students could choose the most interested one to learn. 


\begin{tabular}{|c|c|c|c|c|c|}
\hline \multicolumn{6}{|c|}{ Inpatient department } \\
\hline Time/Date & Monday & Tuesday & Wednesday & Thursday & Friday \\
\hline 8:00-9:00 & \multicolumn{5}{|c|}{$\begin{array}{l}\text { Cataract inpatient department handover in the morning (listen to the yesterday's shift report and learn basic knowledge } \\
\text { on how to treat complicated and special patients) }\end{array}$} \\
\hline 9:00-12:00 & \multicolumn{5}{|c|}{ Common ophthalmic examinations: Visual acuity test, non-contact tonometer, slit-lamp examination, fundus scope } \\
\hline \multicolumn{6}{|c|}{ Basic theory and soft skills } \\
\hline 13:30-14:30 & $\begin{array}{l}\text { Brief lesson: } \\
\text { Anatomy and } \\
\text { Physiology of the } \\
\text { Eyeball (by junior } \\
\text { consultant) }\end{array}$ & $\begin{array}{l}\text { Brief lesson: } \\
\text { Diagnosis and } \\
\text { Treatment of } \\
\text { Cataract (by } \\
\text { resident) }\end{array}$ & $\begin{array}{l}\text { Brief lesson: } \\
\text { Standardization } \\
\text { of Ophthalmic } \\
\text { Data Collection } \\
\text { (by resident) }\end{array}$ & $\begin{array}{l}\text { Brief lesson: } \\
\text { 1. Literature search and full-text } \\
\text { access (by resident) } \\
\text { 2. Clinical trial process (by nurse) }\end{array}$ & $\begin{array}{l}\text { Debate } \\
\text { Questionnaire }\end{array}$ \\
\hline \multicolumn{6}{|c|}{ Outpatient department (Cataract clinic) } \\
\hline \multicolumn{6}{|c|}{ Free time: Free discussion or bonus case discussion } \\
\hline \multicolumn{6}{|l|}{ 16:30-17:30 } \\
\hline \multicolumn{6}{|c|}{ Bonus case 1: Overview of congenital cataracts (Special types of cataracts by junior consultant) } \\
\hline \multicolumn{6}{|c|}{ Bonus case 2: Intraocular flash deposits (Local eye metabolism and sediment by resident) } \\
\hline Bonus case 3 & Jarkling" Catarac & and system & ises by residen & & \\
\hline
\end{tabular}

Figure 1 The detailed schedule of the organized pre-internship curriculum.

\section{Teaching team}

The team consisted of one junior consultant, five residents, and one nurse. Each teacher was responsible for the groupbased learning for 6-8 students.

\section{Evaluating student satisfaction}

Students who participated in the organized pre-internship filled in an 18-item questionnaire. The questionnaire was strictly designed according to previous studies in other areas of medical education (15). The questionnaire was conducted at the end of the week to compare student satisfaction on the organized pre-internship with that on traditional pre-internship. Information presented in the questionnaire consists of several parts (Figure 2). Topics of 15 one-choice questions included: knowledge acquisition (2 items), motivational dimension ( 2 items), group cooperation (2 item), goal specificity (1 item), instructor performance (3 items), organization (1 item), overall rating (2 item), recommendations ( 2 items). Statements were rated on a 4-point scale ranging from "strongly agree" (with the highest score) to "strongly disagree" (with the lowest score). The four-point scale is used to overcome Chinese cultural tendency to choose a "neutral" response and to better reflect the effectiveness and satisfaction of two teaching modes. Two multiple-choice questions were designed to evaluate disadvantages of traditional and organized preinternship. The final part of the questionnaire is one openended problem: What are the advantages and disadvantages of organized pre-internship? Please put forward your valuable opinions.

\section{Data collection}

All data were collected anonymously. The effects of organized pre-internship on student performance were measured by comparison of difference of post- to prelecture scores using a paired $t$-test. Student evaluations to organized pre-internship were measured by an 18item questionnaire, including 15 one-choice question, two multiple-choice question and one open-ended question. To examine whether organized pre-internship had stronger effect on students who had mastered more knowledge in ophthalmology, we divided students into two groups according to their scores of pre-lecture scores. The pre-lecture mean scores was 5.36. The students with pre-lecture scores lower than 6 were defined as the group of students with low knowledge level, and the others were defined as the group of students with high knowledge level. 


\begin{tabular}{|c|c|}
\hline No. & Questionnaire item \\
\hline \multicolumn{2}{|r|}{ One-choice question: A. Strongly agree B. Agree C. Disagree D. Strongly disagree } \\
\hline & Please answer the following questions by comparing the organized pre-internship with the traditional pre-internship \\
\hline 1 & Organized pre-internship helped me to acquire a higher level of knowledge. \\
\hline 2 & Organized pre-internship challenged me to do my best. \\
\hline 3 & Organized pre-internship promoted the learning of essential concepts or skills. \\
\hline 4 & Organized pre-internship promoted effective cooperative learning. \\
\hline 5 & Organized pre-internship help to define daily learning goals. \\
\hline 6 & Organized pre-internship is more effective and motivate. \\
\hline 7 & Overall, I am very satisfied with this organized pre-internship. \\
\hline 8 & Organized pre-internship should be offered more frequently in all teaching hospitals. \\
\hline 9 & I will recommend Organized pre-internship to other students. \\
\hline 10 & The Organized pre-internship module is well organized. \\
\hline 11 & I frequently study with colleagues. \\
\hline 12 & The instructor during the process of organized pre-internship highly facilitated the learning process. \\
\hline 13 & The instructor responded well to questions asked by students. \\
\hline 14 & The instructor encouraged and provided opportunities for discussion. \\
\hline 15 & Organized pre-internship is benefited to promote learning interest and enthusiasm. \\
\hline \multicolumn{2}{|c|}{ Multiple choice question } \\
\hline 16 & Disadvantages of traditional pre-internship? \\
\hline 17 & Disadvantages of organized pre-internship? \\
\hline \multicolumn{2}{|c|}{ Open-ended problem } \\
\hline 18 & What are the advantages and disadvantages of organized pre-internship? Please put forward your valuable opinions. \\
\hline
\end{tabular}

Figure 2 Questionnaire comparing the student satisfaction on the organized pre-internship with that on the traditional pre-internship.

\section{Data analysis}

Differences of post- to pre-lecture scores were compared by paired $t$-test. The effects of baseline knowledge level and gender on lecture score difference were all compared by independent $t$-test. Cumulative histogram was used to analyze questionnaire. $\mathrm{P}$ value $<0.05$ was considered statistically significant for all statistical tests. All analyses were conducted by SPSS software version 22.0 (SPSS Inc., Chicago, IL, USA).

\section{Results}

\section{General performance}

The difference of post- to pre-lecture scores of all participants was $6.21 \pm 2.02(\mathrm{P}<0.0001)$, showing a significant improvement in student performance after organized preinternship (Table 1).

\section{Effects of baseline knowledge level and gender on test performance}

The effect of baseline knowledge level on lecture score difference was analyzed. The difference of post- to prelecture scores of students with low knowledge level $(7.08 \pm 1.85)$ was significantly higher than students with high knowledge level $(4.81 \pm 1.42)$ after organized pre-internship $(\mathrm{P}<0.0001)$ (Table 2). Gender was not related to student performance $(\mathrm{P}=0.750)$ (Table 3).

\section{Student satisfaction}

From August to September 2019, 42 students participated in ophthalmology pre-internship. All students responded to the questionnaire (Figure 3). We found that $69.44 \%$ of the students participating in organized pre-internship strongly agreed that they were satisfied with this mode of pre-internship, while $30.56 \%$ more agreed. Meanwhile, 
Table 1 General test performance of the participants

\begin{tabular}{lc}
\hline Scores $(\mathrm{N}=42)$ & Mean $\pm \mathrm{SD}$ \\
\hline Pre-lecture scores & $5.29 \pm 1.81$ \\
Post-lecture scores & $11.50 \pm 1.66$ \\
Difference in post- to pre-lecture scores & $6.21 \pm 2.02$ \\
\hline
\end{tabular}

${ }^{*}$, statistically significant. SD, standard deviation.

Table 2 Comparison of test performance between students with different baseline knowledge level

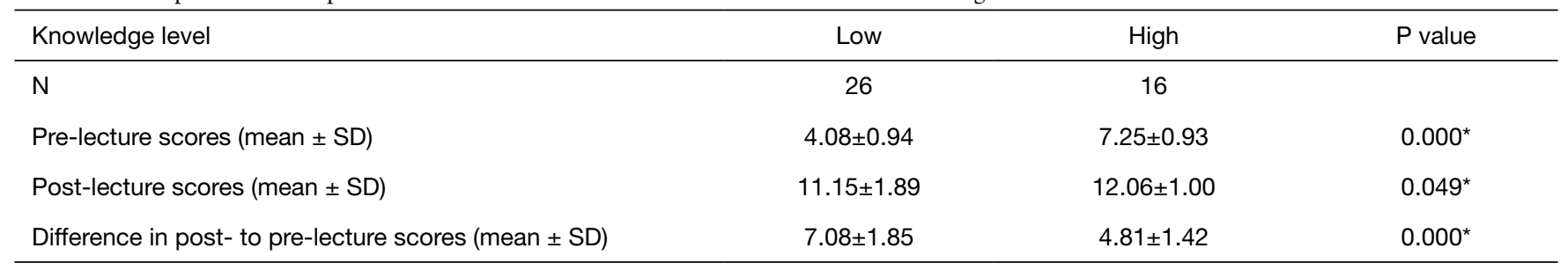

*, statistically significant. SD, standard deviation.

Table 3 Comparison of test performance between students with different gender

\begin{tabular}{llll}
\hline Gender difference & Male & Female & P value \\
\hline $\mathrm{N}$ & 14 & 28 & 0.723 \\
Pre-lecture scores (mean \pm SD) & $5.14 \pm 1.88$ & $5.36 \pm 1.81$ & 1.000 \\
Post-lecture scores (mean \pm SD) & $11.50 \pm 1.35$ & $11.50 \pm 1.82$ & 0.750 \\
Difference in post- to pre-lecture scores (mean \pm SD) & $6.36 \pm 2.02$ & $6.14 \pm 2.05$ & \\
\hline
\end{tabular}

$\mathrm{SD}$, standard deviation.

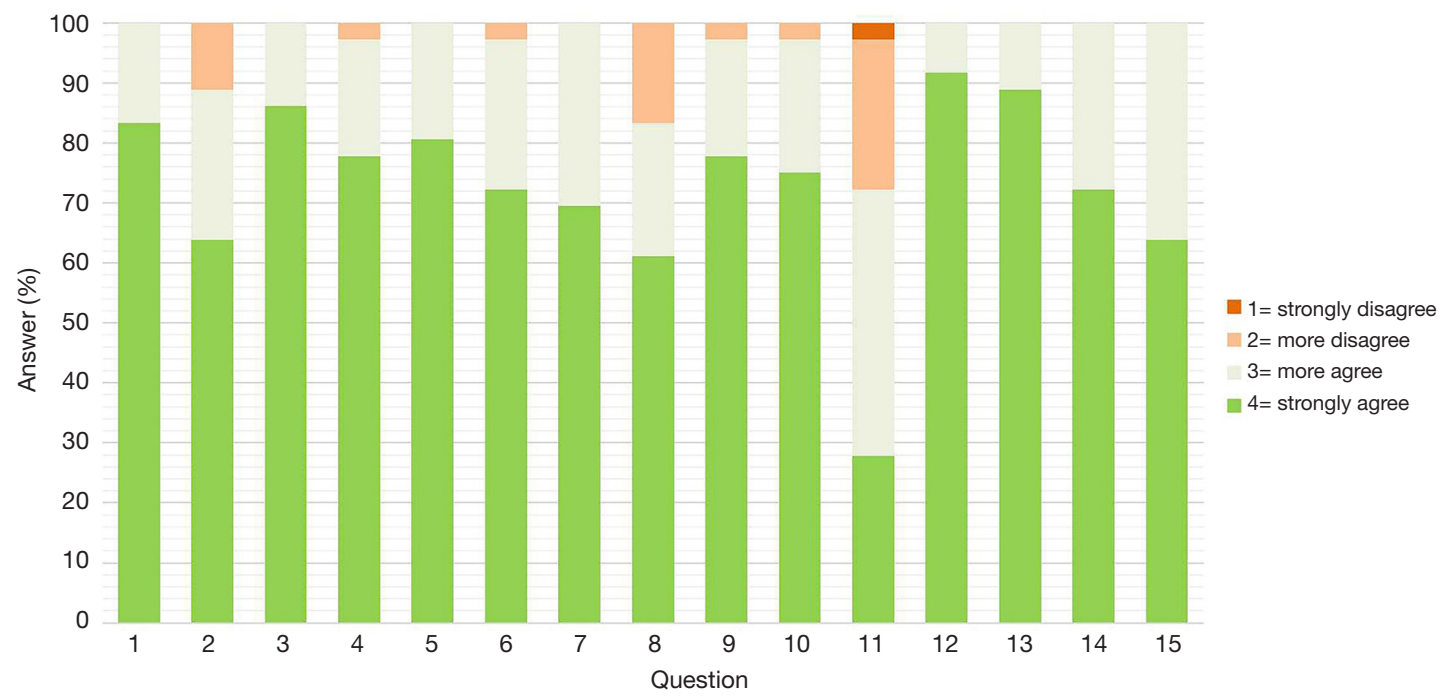

Figure 3 Student evaluations to the organized pre-internship. Each survey question used a four-point scale, 1= strongly disagree (orange); $2=$ more disagree (carneose); $3=$ more agree (light green); $4=$ strongly agree (green). $\mathrm{X}$ axis represents each question. Y axis shows percentage of choices. 
they agreed that instructors played an essential role in the organized pre-internship system.

\section{Student comments on organized pre-internship}

The participants described four main advantages of organized pre-internship. Firstly, organized pre-internship was organizational, rational, humane, comprehensive, purposeful, planned, systematic and efficient. Secondly, the instructors were responsible, instructive and explained knowledge in detail. They also confirmed that curriculum based on rationale of "classroom, clinical practice, sharing and feedback" could help them get good command of knowledge. What's more, they believed that organized preinternship promoted their learning enthusiasm and explored their potential.

Some disadvantages of organized pre-internship were mentioned. The students asked for opportunity to work as "a real doctor", and they thought that the intensity of study was inconsistent every day. They also considered that number of students in a group in the organized preinternship was too large.

In summary, students suggested the pre-internship curriculum to arrange more clinical practice with a smaller study group (less students in one group). They were eager for more activities to observe clinical practice, such as follow-ups and clinics. For ophthalmology, students hoped to extent pre-internship time in order to more profoundly understand this specific medical field.

\section{Discussion}

The significance of early involvement of medical students for clinical practice cannot be overemphasized (16). Preinternship is crucial for medical students and is a rewarding experience (17-19). Most of students participating in medical pre-internship have little medical knowledge and are curious about the role as a clinician (20). They are eager to go to the hospital to learn about the operation of hospital and the routine work in wards and clinics (21). However, due to the lack of well-organized education system and sufficient medical knowledge (22), they need the guidance from senior physicians and the opportunities given by hospital administration. According to these environmental and psychological characteristics, we reformulated traditional unorganized pre-internship and designed an organized curriculum of pre-internship, and compared its pros and cons with traditional pre-internship in several aspects.

We found some encouraging results in student performance. The organized pre-internship significantly improved student performance. In addition, we found that the organized pre-internship had more obvious effect on improving the learning efficiency in the students with low knowledge level. This shows that the organized pre-internship may be more able to stimulate students' enthusiasm for learning, even students with inferior baseline of knowledge can effectively master new knowledge.

Through questionnaire analysis, we found that $69.44 \%$ of students participating in the organized pre-internship strongly agreed that they were more satisfied with this novel mode of pre-internship, while $30.56 \%$ more agreed. The explanations for stronger student satisfaction include that the organized pre-internship clearly defines daily learning goals, integrating important concepts or skills into daily learning and practice, and help to explore potential interest of specialty.

In addition, the participated students highly recognized the teaching team. Previous studies have shown that teachers' guidance is very important for students with little medical knowledge. Many students' mentors provided valuable guidance in solving challenges of a medical career during their pre-internship $(23,24)$. When designing the organized pre-internship curriculum, not only the knowledge level and psychological characteristics of junior medical students were considered, but also great attention was paid to personnel composition of the teaching team. The teaching team was led by a junior consultant, together with several ophthalmic residents and a clinical research nurse. Therefore, each teacher in the teaching team could solve the same clinical problem from different points of view. Furthermore the teachers focused on a variety of research areas and were good at different clinical skills. Arrangement of lecturer for different courses was based on the personal experiences of each teaching member. In our current research, students had concluded that in the process of organized pre-internship, teachers have made detailed and efficient curriculum arrangement according to the needs of students. In the observation of the inpatient department, the theoretical class, the outpatient practice and the debate competition, the teaching team have given students practical and clear guidance, communicated harmoniously with students, and helped students solve various problems in learning. Teachers have greatly improved students' learning efficiency, encouraged and provided opportunities for discussion, and deepened students' understanding of clinical 
problems and medical humanities. There is no doubt that the well-constructed teaching team is a primary condition for the success of the organized pre-internship.

The interpretation of the results should consider the limitations of our study. Since this was the first attempt of organized pre-internship, a long-term study with larger scale could be conducted to provide more information of organized pre-internship. Besides, we did not have a parallel group that students involved in traditional ophthalmology pre-internship to compare their improvement. A historical comparison between traditional and organized preinternship is unavailable in the current study because previous traditional pre-internship in our center did not have the setting of a pre-lecture and a post-lecture test which is necessary for evaluating student improvement. Finally, the improvement in student performance was evaluated by the difference of post- to pre-lecture test scores. The test mainly evaluated the improvement of basic theory and some components such as soft skills were not evaluated.

In conclusion, the organized medical pre-internship shows advantages in improving student performance and promoting learning enthusiasm. We also find out that this model may be more helpful for students with inferior knowledge baseline. The teaching team plays an essential role in the organized pre-internship. The organized preinternship should be further optimized and adapted to various medical field to test its feasibility and effectiveness in medical education.

\section{Acknowledgments}

Funding: This study was funded by the National Key R\&D Program of China (2018YFC0116500 to HL) and the National Natural Science Foundation of China (81873675 to ZL)

\section{Footnote}

Reporting Checklist: The authors have completed the STROBE reporting checklist. Available at http://dx.doi. org/10.21037/atm-20-1651

Data Sharing Statement: Available at http://dx.doi. org/10.21037/atm-20-1651

Peer Review File: Available at http://dx.doi.org/10.21037/ atm-20-1651
Conflicts of Interest: All authors have completed the ICMJE uniform disclosure form (available at http://dx.doi. org/10.21037/atm-20-1651). The authors have no conflicts of interest to declare.

Ethical Statement: The authors are accountable for all aspects of the work in ensuring that questions related to the accuracy or integrity of any part of the work are appropriately investigated and resolved. The study was conducted in accordance with the Declaration of Helsinki (as revised in 2013). All the procedures in this study were arranged strictly with the approval of the institutional review board of Zhongshan Ophthalmic Centre of Sun Yat-sen University (IRB-ZOC-SYSU). Written informed consents have been obtained from all participants.

Open Access Statement: This is an Open Access article distributed in accordance with the Creative Commons Attribution-NonCommercial-NoDerivs 4.0 International License (CC BY-NC-ND 4.0), which permits the noncommercial replication and distribution of the article with the strict proviso that no changes or edits are made and the original work is properly cited (including links to both the formal publication through the relevant DOI and the license). See: https://creativecommons.org/licenses/by-nc-nd/4.0/.

\section{References}

1. Ahmed I, Banu H, Al-Fageer R, et al. Cognitive emotions: depression and anxiety in medical students and staff. J Crit Care 2009;24:e1-7.

2. Berridge EJ, Freeth D, Sharpe J, et al. Bridging the gap: supporting the transition from medical student to practising doctor--a two-week preparation programme after graduation. Med Teach 2007;29:119-27.

3. Brauer DG, Axelson R, Emrich J, et al. Enhanced clinical preparation using near-peer shadowing. Med Educ 2014;48:1116.

4. Alford CL, Currie DM. Introducing first-year medical students to clinical practice by having them "shadow" third-year clerks. Teach Learn Med 2004;16:260-3.

5. Freischlag JA. Shadowing physicians. JAMA 2011;305:2415; author reply 2415-6.

6. Kitsis EA. Shining a light on shadowing. JAMA 2011;305:1029-30.

7. Turner SR, White JS, Poth C, et al. Learning the CanMEDS roles in a near-peer shadowing program: a mixed methods randomized control trial. Med Teach 
2012;34:888-92.

8. Stroh DA, Ray-Mazumder N, Norman JA, et al. Influencing medical student education via a voluntary shadowing program for trauma and acute care surgery. Jama Surg 2013;148:968-70.

9. Kitsis EA, Goldsammler M. Physician shadowing: a review of the literature and proposal for guidelines. Acad Med 2013;88:102-10.

10. Jain A, Luo E, Yang J, et al. Implementing a nurseshadowing program for first-year medical students to improve interprofessional collaborations on health care teams. Acad Med 2012;87:1292-5.

11. Wang JY, Lin H, Lewis PY, et al. Is a career in medicine the right choice? The impact of a physician shadowing program on undergraduate premedical students. Acad Med 2015;90:629-33.

12. Wu DJ, Greenberg PB. A Self-Directed Preclinical Course in Ophthalmic Surgery. J Surg Educ 2016;73:370-4.

13. Wang T, Wang S, Zhang X, et al. Practice and Effect on the Plan of Three Early Educations in Medical Teaching Reform in our University. Researches in Medical Education 2004:17-8.

14. Clark CD. Doctoring Undercover: updating the educational tradition of shadowing. Med Educ Online 2017;22:1265848.

15. Bosner S, Pickert J, Stibane T. Teaching differential diagnosis in primary care using an inverted classroom approach: student satisfaction and gain in skills and knowledge. BMC Med Educ 2015;15:63.

16. Teagle AR, George M, Gainsborough N, et al. Preparing medical students for clinical practice: easing the transition. Perspect Med Educ 2017;6:277-80.

Cite this article as: Wu D, Xiang Y, Wu X, Chen J, Zou Y, Liu Z, Lin H, Liu Y. Modified organized ophthalmology pre-internship in China. Ann Transl Med 2020;8(21):1426. doi: 10.21037/atm-201651
17. von Below B, Hellquist G, Rodjer S, et al. Medical students' and facilitators' experiences of an Early Professional Contact course: active and motivated students, strained facilitators. BMC Med Educ 2008;8:56.

18. Langenau E, Frank SB, Calardo SJ, et al. Survey of Osteopathic Medical Students Regarding Physician Shadowing Experiences Before and During Medical School Training. J Med Educ Curric Dev 2019;6:1486495730.

19. Dai L, Wu Y, Zheng D, et al. Investigation of foreobservation from 181 junior medical students and exploration of teaching methods for fore-observation. China Higher Medical Education 2007:48-9.

20. Tien M, Aiudi CM, Sviggum HP, et al. A peer-designed selective in anesthesiology, critical care, and perioperative medicine for first- and second-year medical students. J Clin Anesth 2016;31:175-81.

21. Dornan T, Littlewood S, Margolis SA, et al. How can experience in clinical and community settings contribute to early medical education? A BEME systematic review. Med Teach 2006;28:3-18.

22. Iwata K, Gill D. Learning through work: clinical shadowing of junior doctors by first year medical students. Med Teach 2013;35:633-8.

23. Straus SE, Johnson MO, Marquez C, et al. Characteristics of successful and failed mentoring relationships: a qualitative study across two academic health centers. Acad Med 2013;88:82-9.

24. Mattes MD, Gerbo R, Dattola RM. Tumor Board Shadowing for Medical Students as a Means of Early Exposure to Multidisciplinary Oncology Education. J Am Coll Radiol 2017;14:253-5. 